\title{
A análise do uso dos jogos para o desenvolvimento do pensamento lógico-matemático nos anos iniciais do ensino fundamental
}

\author{
Analysis of the use of games for the logical-mathematical development \\ thinking in the early years of elementary school
}

\author{
Ruhena Kelber Abrão \\ kelberabrao@gmail.com
}

João Alberto da Silva

kelberabrao@bol.com

\begin{abstract}
Resumo
Este trabalho parte da ideia de que muitas vezes os professores de matemática percebem o uso dos jogos em sala de aula apenas de forma recreativa e não como uma importante ferramenta pedagógica capaz de estimular a aprendizagem de conceitos e habilidades matemáticas como seriação, sequência, simbolização e correspondência. A aplicação dos jogos em sala de aula rompe com o modelo tradicional de ensino baseado na explanação, memorização e repetição dos exercícios, pois parte direto da experimentação. Em virtude de grande parte dos professores acreditarem que a aprendizagem ocorre devido ao processo de repetição e não por uma atividade assimiladora, é que muitos alunos assumem uma posição passiva em relação à aprendizagem diferentemente do que ocorre com o uso dos jogos fazendo com que o exercício alcance o patamar de desafio. Desta forma, através da análise destes buscou-se verificar como os jogos contribuem para o ensino de matemática.
\end{abstract}

Palavras-chave: Aprendizagem. Jogos. Educação matemática. Classificação. Processos Cognitivos.

\begin{abstract}
This work starts from the idea that often Mathematics teachers perceive the use of games in the classroom only recreationally and not as an important educational tool capable of stimulating the learning of mathematical concepts and skills as ranking, sequencing, correspondence and symbolization. The application of games in the classroom breaks with the traditional model of education based on explanation, memorization and repetition of the exercises, because starts from direct experience. In this way, many teachers believe that learning occurs due to the process of repeating an activity and not by assimilation, and because of that many students take a passive position in relation to learning in contrast to what occurs with the use of games which make the exercise to reach the level of a challenge. Thus by examining these we tried to see how the games contribute to the teaching of Mathematics.
\end{abstract}

Keywords: Learning. Games. Mathematics Education. Classification. Cognitive Process. 


\section{Introdução}

O ensino de matemática, desde o surgimento da escola enquanto instituição tem sido um desafio para diversos educadores e educandos. A sistemática de ensino, em geral, foi pautada em modelos de exercícios pré-fabricados, baseados apenas na repetição e memorização, desvinculado da realidade, na qual os alunos não veem aplicabilidade com o cotidiano. Nesse sentido, Kamii (1982), aponta que o saber não está apenas nos conteúdos escolares, não havendo sentido nas listas de exercícios desenvolvidas a partir sempre do mesmo raciocínio. Desta forma, a inteligência se constitui não pelo acúmulo de informações, mas sim pelo processo de reorganização, que segundo Piaget (1975b), pode ser entendido como processo de sistematizar as informações e experiências em estruturas lógicas, psicológicas ou de ação, denominado de esquemas.

Em geral, pode-se superar o ensino tradicional quando o professor elenca maneiras de fazer com que os alunos sintam-se convidados a pensar um passo a frente do que foi ensinado, isto é, para além dos exercícios. É comum o desinteresse e dificuldade dos alunos para com a aprendizagem da matemática nos anos inicias do Ensino Fundamental. Sendo assim, há de se estimular o aluno aprendente a querer saber mais sobre o desconhecido, dado que o desinteresse pela escola não deve ser visto como algo normal e rotineiro, fator este que muitas vezes reflete falhas na metodologia de ensino utilizada pelo professor. Muitas vezes estas falhas devem-se à limitada visão dos professores dos anos iniciais sobre a gênese da construção dos sistemas numéricos e das quatro operações.

No primeiro e no segundo ano dos anos iniciais, o enfoque de ensino se constitui na alfabetização, isto é, na aquisição do domínio da língua materna, tanto pela oralidade quanto pela escrita. No entanto, a alfabetização não se restringe apenas ao campo das letras, nesse período escolar deve-se alfabetizar cientificamente as crianças, em todas as áreas do saber, incluso a matemática, que se constitui também como uma linguagem que possui seus códigos e símbolos.

A ideia de número, segundo Piaget (1975a), é uma construção interna do sujeito que ocorre a partir das relações que são estabelecidas na leitura do mundo. Quanto mais diversificadas forem as experiências que o sujeito mantém na interação com o meio, maior as possibilidades de compreensão. Ainda para o autor, o número é construído por cada sujeito a partir de todos os tipos de relações que cada um cria com os objetos.

Desde pequeninas, as crianças adentram no mundo dos números, na maioria das vezes, sem compreender o real significado, pois na escola estão acostumados na repetição de sequências 
numéricas sem conseguirem estabelecer relação entre quantidade e símbolo. O simples fato de a criança conseguir repetir sequencialmente os numerais não garante a compreensão do sentido ordinal e cardinal dos números.

Cada vez mais educadores querem que seus educandos desenvolvam a habilidade de construir a compreensão dos conceitos matemáticos de forma que interpretem o significado destes, reconhecendo quando devem ser aplicados, bem como a limitação desta aplicabilidade. A partir disto, muito professores passam a utilizar ferramentas com intencionalidade pedagógica que divergem ao modelo tradicional de ensino, com vistas a melhorar o desempenho dos alunos, surgindo assim o uso dos jogos na sala de aula. Nos primeiros anos do Ensino fundamental, vemos a maioria das crianças centradas apenas na ânsia pelo brincar, na qual esta brincadeira muitas vezes vai de encontro às atividades estabelecidas pelas normas, regras e pelo currículo escolar. A normatização de certas atitudes na escola, ao invés de proporcionar as crianças sentimentos como liberdade e autonomia tendem a padronizar os comportamentos e as aprendizagens que devam ocorrer naquele espaço, renunciando a dicotomia que o jogo proporciona, isto é, a liberdade e o prazer.

Kamii (1982), em seus estudos relata que a partir do fazer pedagógico cotidiano, as crianças, ao chegarem à escola, geralmente, gostam de matemática. Entretanto, o desejo pelo aprender decresce em decorrência do avanço escolar das mesmas, devido à forma pela qual os conhecimentos são trabalhados em sala de aula. No ambiente escolar, em grande parte das vezes, os jogos são tidos como atividades que causam apenas diversão. Em outro estudo Kamii (2004) relata que os professores estão passando a perceber os jogos como uma atividade capaz de trabalhar conceitos e conteúdos de diversas áreas, inclusive os de matemática.

Nesse sentido, a escola precisa desenvolver ações que valorizem o ensino de matemática, fazendo a interrelação do conhecimento inicial e prévio que a criança possui, com as situações nas quais os conceitos matemáticos, ditos formais, são trabalhados. Diversos educadores têm em seus discursos que os procedimentos matemáticos tidos como informais, expressados pela criança através da oralidade, devem ser substituídos pelos algoritmos e pelas regras ensinadas na escola. 


\section{A matemática e o desenvolvimento cognitivo}

Em seus estudos Piaget (1975b), elencou quatros estágios do desenvolvimento cognitivo pelos quais a criança passa: sensório motor, pré-operacional, operatório concreto e operacional abstrato. Em cada um desses estágios, a criança, ao portar-se de maneira diferente, desenvolve habilidades específicas a cada fase da vida.

Para Goulart (1999), no primeiro estágio do desenvolvimento, isto é, do nascimento até os 2 anos, é o período em que se verifica a coordenação sensório-motora de ação baseada na evolução da percepção da motricidade. Nessa fase, a criança passa a perceber a importância da repetição das ações, seja ao arremessar um objeto para ter domínio da ação ou chorar diversas vezes para obter resultados como alimento e companhia. No que tange à matemática, a criança nesse período passa a desenvolver o raciocínio, ampliando a noção de espaço e de tempo, percebendo as áreas ao seu redor e noção básicas de tempo como dormir e acordar.

Piaget (1975b) denominou o segundo estágio de desenvolvimento como simbólico ou préoperatório, compreendido por volta dos 2 aos 6 anos de idade. Goulart (1999) definiu este estágio como intuitivo, pois é dominado pela fantasia, o devaneio e a imaginação.

Quando a criança chega na escola, passa a querer encontrar as respostas para todas as suas dúvidas, e, rapidamente, se depara com uma escola cheia de respostas fabricadas que não são capazes de estimular a investigação, provocando na criança acomodação, entendido por Piaget (1975b), como a re-estruturação dos esquemas de assimilação, isto é, a capacidade da criança em adaptar-se ao ambiente. No que tange aos conceitos matemáticos, a criança inicia sua aproximação com o Sistema de Numeração Decimal e com as quatro operações básicas de forma sistêmica passando a seguir as regras e não mais a intuição. Muitas são as dificuldades enfrentadas na compreensão destes conceitos, muitas vezes a aversão à matemática surge nesta etapa da vida.

O terceiro estágio, elencado como operatório concreto, variável dos 7 aos 12 anos de idade segundo Elkind (1978) é caracterizado pela possibilidade da criança fazer com cabeça o que antes fazia com as mãos. A forma pela qual a escola disponibiliza os conhecimentos, não os relacionando de forma concreta acaba por dificultar a compreensão dos alunos, fazendo com que a resistência à matemática comece a se consolidar.

$\mathrm{Na}$ escola, este estágio é explicito quando os conteúdos são trabalhados de forma sequencial sem articulação com o cotidiano e a realidade. Os problemas matemáticos são formulados sem exigir a interpretação e contextualização dos mesmos. Passa-se a trabalhar com as 
coleções, seriações e classificações. A criança começa a obter um avanço significativo na organização e compreensão do mundo, aumentando consequentemente a quantificação e ampliação da capacidade de raciocínio. Em relação ao ensino de matemática, a característica mais marcante é a aquisição da noção de conservação, isto é, a criança passa a ser capaz de perceber que algumas das características dos objetos se mantêm, mesmo com a ocorrência de uma transformação.

O quarto estágio do desenvolvimento, os das operações formais, vai, mais ou menos, dos 12 anos de idade em diante. Nesse momento ocorre o desenvolvimento das operações de raciocínio abstrato, na qual o sujeito passa a se libertar inteiramente do objeto, passando-o a representá-lo, operando agora com a forma em contraposição a conteúdo, situando o real em um conjunto de transformações. (FLAVELL, 1975).

A partir desse estágio, a criança passa a iniciar os processos de pensamento hipotéticodedutivos. O sujeito passa a ser capaz de raciocinar corretamente sobre proposições em que acredita ou não. Neste momento, começam a se desenvolver as capacidades lógicas e de representação simbólica tal como muitos adultos utilizam. Na escola, a criança ao resolver os problemas passa a raciocinar por meio de uma lógica intuitiva, considerando durante a resolução dos problemas, diversas alternativas possíveis escolhendo então a mais apropriada.

Tanto na escola quanto no senso comum, a matemática é tida como o "Bicho Papão", sendo uma ciência feita apenas para os alunos portadores de altas habilidades. É sabido o alto índice de reprovação e evasão que a matemática proporciona, o que não é exclusivo do Brasil, mas também acontece em diversos países do mundo, fazendo com que o título de disciplina dura e sem significado seja ratificado diariamente. Poucos educadores e educandos percebem que a matemática está presente em quase todas as atividades e no raciocínio humano. Todos nós dependemos de cálculos mentais para a resolução de problemas, mesmo que, às vezes, não nos pareçam de forma clara, pois dependemos dos números, das medidas, horas, quantidades entre outros conceitos matemáticos para realizarmos as ações diárias necessárias à vida.

Ao longo da história da educação matemática, criou-se o mito de que se a criança aprender as quatro operações fundamentais, adição, subtração, multiplicação e divisão ela aprenderá matemática. $\mathrm{Na}$ verdade, está é uma ciência que prima pelo desenvolvimento do raciocínio, diferentemente do que ocorre, visto que o ensino das operações baseia-se em memorização e repetição na resolução que deveria exigir raciocínio, no qual o resultado é o sujeito perceber que não assimilou corretamente os conceitos que supostamente foram aprendidos. 
Kamii (1982) relata que mesmo que o professor passe a utilizar acessórios como o material dourado, ábaco, quadro de lugar e valor, as crianças continuam com as mesmas dificuldades. Passa-se a ter então a ideia de que o problema não está nas operações e sim na tabuada, fazendo com que o professor trabalhe ainda mais a repetição e a memorização. Entretanto, a compreensão dos conceitos matemáticos continua deficiente, visto que a escola, na maioria das vezes, não trabalha as habilidades necessárias na construção do conhecimento matemático, como classificação, correspondência, simbolização e sequência. Estas habilidades são o elo condutor para a compreensão e aplicabilidade dos conceitos matemáticos, devendo estas terem mais ênfase nos conteúdos programáticos trabalhados na escola, contribuindo para a solidificação e apropriação dos conceitos matemáticos pela criança (KAMII, 1982).

\section{Jogo no ensino da matemática}

Segundo Piaget (1975a), a Matemática deve ser compreendida como um modo de pensar, devendo ser estimulada nas pessoas nas mais tenras idades. Sendo assim, os jogos são excelentes recursos para despertar o modo de pensar e de raciocinar das crianças.

Macedo (2005) destaca que o jogo acompanha o ser humano desde a infância até a velhice, variando de acordo com o interesse e desenvolvimento cognitivo de cada um. Através dos jogos viabiliza-se a busca de informações, a interação com o outro, com o pensamento espontâneo, com o improviso e com o formal, servindo de projeção, bem como de suporte as descobertas. O jogo possui um caráter formativo e informativo, porém pode-se praticar o jogo pelo simples fato de jogar, apenas como uma atividade recreativa, sem a intencionalidade pedagógica de se trabalhar conteúdos. Quando o objetivo é a aprendizagem, o jogo deverá ser planejado e orientado a fim de se atingir os objetivos propostos. Para que ocorram mudanças significativas, o professor deverá ter consciência que ele é o mediador deste processo e o aluno é o sujeito cognoscente. (GOULART, 1999).

Ao utilizar os jogos, o professor proporciona uma ruptura no modelo tradicional de ensino baseado apenas na exposição dos conteúdos. A criança enquanto jogador trabalha a capacidade de articular perguntas, buscar soluções, avaliar seus comportamentos, resolver

problemas, e, principalmente, a pensar sobre o seu próprio ato de pensar, isto é, a metacognição. (FLAVELL, 1975). 
Segundo os Parâmetros Curriculares Nacionais (PCN), o fato dos jogos provocarem nos alunos um desafio genuíno, é uma das principais características desta ferramenta, proporcionando interesse e prazer pela disciplina de matemática. De acordo com Macedo (2005), a noção de jogo aplicado à educação, mais especificamente na sala de aula, desenvolveu-se de maneira vagarosa, penetrando tardiamente no âmbito escolar, sendo sistematizada com atraso, porém trazendo transformações significativas.

Brougère (2000) defende que o jogo não é um recurso tão recente, suas primeiras aparições estão datadas no Renascimento. Segundo este autor, antes de se pensar o jogo como um lugar possível de educação, havia três modos de estabelecer as relações entre este e a educação. $\mathrm{O}$ primeiro remetia ao pensamento aristotélico, o de recreação, o jogo seria o relaxamento indispensável. O segundo aparece na educação como um artifício pedagógico, no qual o interesse que a criança manifestava pelo jogo era transformado em formas de ensinar. Já o terceiro era tido como uma atividade que permitia ao pedagogo observar bem como compreender a personalidade da criança adaptando-a ao ensino.

O jogo a partir de seu vínculo com a educação é justificado no espaço educacional como necessário, como oposição e complementaridade do trabalho intelectual da criança. A recreação passa a ser tratada como um momento escolar não consagrado à educação, mas complementar.

No século XVI, o jogo surge na educação de crianças durante o processo de ler e escrever sendo um suporte atrativo. Passa-se utilizar os aspectos do jogo para estimular a criança na realização e empenho de suas atividades escolares, os chamados artifícios pedagógicos.

O professor antes de trabalhar com os jogos na sala de aula deve testá-los, para poder prever as possíveis dificuldades dos alunos. Cabe ressaltar que na hora de escolher os jogos dois aspectos devem ser levados em conta: serem interessantes e desafiadores, sendo o jogo escolhido nem tão fácil demais e nem tão difícil, para que os alunos não se sintam desestimulados. (GOULART, 1999).

Durante o jogo, não existem ações passivas, todos são ativos durante este processo. Nota-se que ao jogar, aqueles que o fazem apresentam um melhor desempenho frente aos processos de aprendizagem. A metodologia encontrada por muitos educadores é utilizar os jogos apenas no final da aula para que os alunos se sintam motivados a voltar no dia seguinte. 


\section{Jogos para classificação}

A habilidade de classificação começa a se desenvolver na criança no momento em que esta começa a falar. Através da interação com o meio, a criança passa a estabelecer relações com os objetos, a observar as formas e as quantidades. Ainda que de forma elementar, a partir do contato ou manuseio dos objetos, elas passam a formar conjunto atribuindo a eles alguma semelhança. $\mathrm{Na}$ escola, comumente os professores solicitam aos estudantes formarem conjuntos de canetas, lápis, observando as cores ou formas. Esse processo embora pareça simples, não o é, pois, à medida que a criança passa a classificar, surgem outras características, como, por exemplo, conjunto de lápis coloridos, sem ponta, tons claros, tons escuros, em que estas características muitas vezes causam dificuldade na compreensão dos critérios de inclusão e classes e na relação de compreensão com o meio.

Segundo Kamii (1982), o conceito de classificação pode ser entendido como a repetição de conjuntos de objetos num determinado número de conjuntos parciais coordenados e subordinados, isto é, classificar e ordenar, a partir de características comuns, separando-as por grupo. A partir do momento em que a criança passa a identificar o nome dos objetos ela passa a estabelecer uma ação complexa, visto que, além de memorizar a palavra que nomeia o objeto, passa a desenvolver a capacidade de assimilar as diferenças e semelhanças entre eles. É neste exato momento em que a criança passa a perceber que um carro é diferente de um ônibus - ambos são meios de transporte, porém possuem semelhanças e características distintas que os permitem serem classificados e pertencerem ou não a um mesmo conjunto.

Coordenar a habilidade de classificação quando esta envolve mais de um critério tornar-se uma atividade muitas vezes complexa para a criança. Nesse sentido, os jogos possibilitam que as relações sejam feitas de forma lúdica ajudando na construção do conceito matemático. Os jogos que envolvem os conceitos de classificação devem propiciar a resolução de situações problemas, como por exemplo, no Pega Varetas, um jogo clássico entre crianças. O jogo começa quando um dos participantes pega todas as varetas coloridas na mão, fechando-a, formando uma espécie de feixe. Logo após, o jogador abre a mão largando as varetas sobre uma superfície plana. O objetivo do jogo é tentar apanhar uma a uma cada vareta até não restar mais nenhuma. Caso o jogador da vez movimente mais do que uma vareta ao tentar pegá-la, passará a vez para o próximo adversário.

A cada vareta é atribuído um valor numérico diferenciado, sendo a de cor preta a com o maior valor, tendo apenas uma no jogo inteiro, que, de acordo com a vontade do jogador pode ser utilizado como instrumento de apoio para pegar as demais. A criança, ao brinca com este 
jogo, utiliza-se da classificação, pois escolhe as varetas a serem pegas de acordo com a cor e o valor numérico que fora atribuído. O Vencedor é o jogador que mais pontos somar e não aquele que mais varetas possuir.

\section{Jogos para sequência}

A habilidade de sequência deve estabelecer uma relação direta com a seriação. Nesse sentido, a sequência não esta de certa forma ligada a critérios pré-definidos de ordem crescente ou não. No entanto, para a seriação, este critério é tido como fundamental. Na seriação, a criança ordena segundo alguma característica como colocar os objetos em um determinado conjunto, podendo ser este por ordem de tamanho, isto é, do menor ao maior ou vice-versa. Segundo Piaget (1975b), a habilidade de sequência é considerada como invariante, porém, a idade em que aparece um dado estágio pode variar consideravelmente.

De certa forma, todos os conteúdos matemáticos são construídos e organizados de acordo com uma sequência. Estas acompanham todo o processo de construção de conceitos matemáticos, mesmo não possuindo uma única regra, pois esta varia de acordo com ao desenvolvimento cognitivo de cada indivíduo.

As atividades envolvendo, por exemplo, cartões coloridos, isto é, um preto, um branco, um preto, um branco ou formas geométricas como, quadrado, círculo, círculo, quadrado, possuem um padrão de regularidade: basta encontrar o critério que foi estabelecido e se irá definir o restante da sequência. A criança, ao se deparar com atividades desta natureza, passa a construir com maior facilidade o conceito de número, para, posteriormente, compreender e aplicar as operações básicas.

Nesse sentido, corroboramos o pensamento de Kamii (1982), que o número não é ensinado na escola, mas sim construído pela criança. Neste processo, o professor pode ser um problematizador no processo de aprendizagem do aluno.

As operações fundamentais da Matemática podem ser apresentadas com atividades de conjuntos, sobrepondo ou extraindo elementos, para, em seguida, observar os novos conjuntos formados. Através do auxílio de materiais concretos, os alunos podem compreender melhor os objetos operacionalizando-os de maneira que compreendam os conjuntos construídos e as operações realizadas, promovendo experiências que desenvolvem a habilidade de seriação para a resolução de situações problemas. 
Como exemplo de jogo que trabalha a habilidade de sequência e seriação citamos o Oito Maluco. O nome justifica-se porque a carta número 8 é considerada o coringa do jogo. $\mathrm{O}$ número de jogadores é variável, sendo necessário o mínimo de participantes comuns a todos os jogos: dois. No entanto, quanto mais jogadores, menor será o ritmo da partida. Cada um receberá 7 cartas, de um baralho contendo 52. As cartas restantes ficam sobre a mesa com a face para baixo. Uma carta é virada para o início da partida. O primeiro jogador irá pôr uma carta que coincida com o número ou com o naipe da carta inicial, isto é, se a carta é um 3 de espadas, o seguinte poderá colocar ou uma carta que tenha o mesmo naipe ou o mesmo número. O jogador também pode utilizar-se a qualquer momento do coringa, caso o tenha. Caso o participante não possua nenhuma carta compatível na jogada deverá comprar uma do monte, até que consiga uma que possa ser jogada.

Vence o jogo aquele que primeiramente se livrar de todas as cartas da mão. Uma vez que o monte acabe sem que nenhum jogador tenha vencido, o mesmo deverá ser embaralhado e colocado virado, restabelecendo assim o monte.

A criança, ao jogar o Oito Maluco trabalha com as habilidades básicas de sequência, valendose ou do número, ou do naipe das cartas. Para que ela seja vitoriosa na partida, deverá lidar com o raciocínio de prever as cartas que já foram jogadas, calculando mentalmente as supostas que seus colegas possuem.

\section{Jogos de simbolização}

Segundo Kamii (2004), apenas nós, seres humanos, através da simbolização, temos a capacidade de representar uma experiência de forma tanto verbal quanto não verbal. Os símbolos se constituem, como elementos fundamentais na construção dos conceitos matemáticos, dado que toda a linguagem matemática é representada de forma simbólica: os numerais, os sinais, as medidas, as quantidades entre outros. Esses símbolos criados socialmente têm a função não apenas de facilitar a expressão, mas também a comunicação.

De acordo com Piaget (1975b), símbolos são entendidos como objetos que representam ou tomam lugar de qualquer coisa diferente, podendo assumir diversas formas, desde objetos concretos até marcas escritas no papel. O processo de simbolização é tido como de extrema importância para o ensino de matemática, pois estes estão presentes em todos os conceitos desta ciência. 
Citamos o jogo de Dominó, para trabalhar com as habilidades de simbolização, no ensino de matemática para crianças. O total de peças, ou pedras, é de 28, distribuídas em 7 para cada participante, as restantes ficam para serem compradas. O jogo inicia-se com o jogador que possui a peça $6 / 6$, caso ninguém a tenha parte-se para 5/5, 4/4 assim por diante. Caso a partida comece com o 6/6, o jogador seguinte deverá colocar alguma pedra que contenha o número 6. Caso não o tenha, deverá comprar do monte até achá-la. Quando as peças do monte acabarem, o participante deverá passar a sua vez para o próximo. Às vezes, acontece de em uma mesma partida as duas pontas do jogo o número solicitado não exista mais, nem na mão de nenhum participante e nem no monte. Sendo assim, o jogo é dado por encerrado, ganhando a partida aquele que menos peças tiver na mão. Outra forma de encerrar essa partida é contar os pontos das peças que ficaram nas mãos, sendo o vencedor aquele que menos pontos tiver.

Ao trabalhar com o jogo de dominó na sala de aula, a criança projeta simbolicamente nas pedras os números $6,5,4,3,2$ e 1 . Desta forma, ela é capaz de realizar a leitura do símbolo e representar a ideia expressa, facilitando a compreensão e facilitando a aprendizagem.

\section{Jogos de correspondência}

Kamii (2004) define a habilidade de correspondência como de dois tipos: biunívoca ou usual. A correspondência biunívoca é também denominada como um a um, isto é, associar a cada objeto de uma coleção um objeto de outra coleção. Historicamente, o homem utilizou a correspondência um a um para resolver os problemas de cálculos, sendo de extrema importância para o surgimento da noção de número. Já a correspondência usual estabelece relação entre os elementos através da utilidade dos mesmos, na qual os objetos poderão ser relacionados entre os grupos ou conjuntos por características como peso, tamanho, cor entre outros.

Para trabalhar a habilidade de correspondência, pensou-se num jogo denominado O Mais Alto e O Mais Baixo. O jogo parte do princípio que as crianças percebem desde muito cedo que umas são mais altas do que outras. Desta forma, é interessante propor uma atividade que compare as alturas através da observação.

Começa-se com a frase: “Quem é mais alto que você?". Um aluno deverá ser escolhido para ir à frente. O professor diz: “Esta é a Maria, quem é mais alto ou mais baixo que ela?". A cada criança que vai levando, vai-se marcando na parede com um giz a altura dela. Para cada marca, o nome da criança é escrito. Pode-se trabalhar tanto a correspondência biunívoca 
comparando uma criança com a outra, bem como a usual, comprando-as dentro do grande grupo. Nesse sentido, esse tipo de jogo contribui para auxílio do desenvolvimento cognitivo da criança, através da resolução da incógnita que é: mais alto e ou mais baixo que eu?

\section{Jogos de avaliação}

Para grande parte dos professores a avaliação é sem dúvida o grande problema que permeia o ensino da Matemática, gerando medo e angústia em grande parte dos alunos. Goulart (1999) defende que se o conhecimento matemático tem uma forma própria de produção e expressão, então ele deve requerer uma abordagem que considere as características desse conhecimento, se isso realmente ocorrer, a avaliação da aprendizagem não será independente do conteúdo.

Os jogos enquanto instrumento avaliativo tende a melhorar o processo de ensino aprendizagem, podendo ser empregados para construir autoconfiança e motivação. Qualquer jogo, por mais simples que seja, é capaz de gerar habilidades como destreza e competência, desencadeando emoções e sentimentos que vão desde a alegria da vitória até a decepção da derrota, despertando aquilo que Piaget nomeou como autônima moral e intelectual. (PIAGET, 1975a).

Nesse sentido, um perfeito jogo para desenvolver a habilidade de avaliação na criança é o boliche. Primeiramente, o professor irá explicar como se joga o boliche. Para construir essa atividade, os pinos poderão ser confeccionados com garrafas pet. A cada pino uma tira de uma cor, totalizando o total de 20 pinos divididos em 4 cores. Como bola pode-se usar uma bola pequena que a criança consiga segurar com apenas uma das mãos. O professor dividirá a turma em duas grandes equipes. Cada equipe terá dez pinos de duas cores. Cada jogador deverá vivenciar o movimento e arremesso da bola pelo menos uma vez, tentando derrubar o máximo de pinos possíveis. O professor pode atribuir valores diferenciados a cada pino ou a cada cor.

Nesse momento, o professor pode começar a trabalhar as operações básicas, por exemplo, os pinos podem estar espalhados de forma aleatória na quadra, e a cada arremesso acertado adiciona-se à equipe 2 pontos e a cada errado subtraí-se 1 ponto. Após alguns arremessos irão começar as contas de multiplicação, pois uma equipe derrubou 7 pinos ( 7 x $2=14$ pontos), porém errou três arremessos ou 3 pinos ficaram em pé $(3 \times 1=3$ pontos). Nesse caso a equipe terá (14 pontos -3 pontos $=4$ pontos). A cada partida o professor poderá utilizar a criatividade para formar equipes e maneiras de pontuar as jogadas. 


\section{Considerações}

Os jogos não têm tido destaque entre os conteúdos escolares, principalmente no que se refere ao ensino de matemática nas séries iniciais. Muitas vezes, estes são vistos apenas como passatempo. Quando utilizamos nas aulas de matemática, são usados apenas para exercícios de repetição, e não como ferramenta pedagógica capaz de estimular a construção de habilidades específicas da Matemática, como classificação, seriação, simbolização e correspondência. Em grande parte das vezes, os alunos percebem a aula de jogos como atividades recreativas, e os professores, na maioria das vezes não conseguem fazer relação entre as atividades e a construção de conceitos.

Uma das principais primícias dos jogos é a evolução do grau de dificuldade, exigindo que o jogador passe a desprender cada vez mais energia, atenção e reflexão para com o jogo, proporcionando assim, uma gama de alternativas e possibilidades que são capazes de gerar aprendizagens. No entanto, as aprendizagens só são capazes de ocorrerem se o condutor do jogo, ou seja, o professor seja capaz de explorá-lo, fazendo com que os alunos modifiquem comportamentos e atitudes, proporcionando um amadurecimento cognitivo, contribuindo para a construção de conceitos Matemáticos.

$\mathrm{Na}$ maioria das vezes, os professores preferem continuar com a postura tradicional de ensino nas aulas de matemática, baseados no esquema explicação, exemplificação e exercitação de modelos pré-fabricados, muitas vezes a partir do livro didático, baseados na repetição e memorização. Os jogos vêm ao encontro desta metodologia, pois partem direto da experimentação, quebrando com a sistemática do modelo tradicional de ensino, na qual muitos professores temem não saber utilizar os jogos de forma didática, causando assim a tão temida bagunça e confusão, perdendo o sonhado domínio da sala de aula.

Utilizar os jogos como metodologia de aprendizagem requer dos professores trabalho, pois estes deverão articular os conteúdos programáticos com as brincadeiras, prevendo que por vezes virão também sentimentos como revolta, incerteza, medo. Ao invés de auxiliar no processo de aprendizagem, estes sentimentos podem criar barreiras no processo, para isto, dever-se-á ter um planejamento flexível, prevendo as mais diversas ações e reações.

Nota-se que com o uso dos jogos, ocorrem mudanças no processo de ensino aprendizagem, pois acontecem primeiramente momentos de memorização, de repetição, reflexão e por fim, o de construção de conceitos. A educação Matemática passa a ser trabalhada sob outras óticas, aproximando-se da linguagem materna. Desta forma, os jogos são uma das poucas atividades 
presentes na rotina das crianças tanto no ambiente escolar quanto fora dele, possibilitando aos educadores explorarem o mundo das crianças, associando função pedagógica de aprendizagem à função do prazer funcional que o jogo proporciona.

\section{Referências}

BRASIL. Ministério da Educação e do Desporto. Secretaria de Educação Fundamental. Parâmetros Curriculares Nacionais: Matemática. Brasília, 1997.

BROUGERE, G. Jogo e educação. Porto Alegre: Artes Médicas, 2000.

ELKIND, D. Crianças e Adolescentes: Ensaios Interpretativos sobre Piaget. São Paulo: Zahar, 1978.

FLAVELl, J. H. A psicologia do desenvolvimento de Jean Piaget. São Paulo: Pioneira, 1975.

GOULART, Í. Piaget experiências básicas para utilização pelo professor. Petrópolis: Vozes, 1999.

KAMII, C. Aritmética: novas perspectivas implicação da teoria de Piaget. Campinas, SP: Papirus. 1992.

A criança e o número. Campinas, SP: Papirus, 2002.

MACEDO, L.; PETTY, A. L. S.; PASSOS, N. C. Aprender com jogos e situações problema. Porto Alegre: Artmed, 2000.

Os jogos e o lúdico na aprendizagem escolar. Porto Alegre: Artmed, 2005.

PIAGET, J. A formação do símbolo na criança: imitação, jogo e sonho, imagem e representação. Rio de Janeiro: Zahar, 1975a.

SZEMINSKA, A. A gênese do número na criança. Rio de Janeiro: Zahar, 1975b. 